\title{
Knee Arthroplasty: With or Without Patellar Component?
}

\author{
Sólyom Árpád1', Király Ildikó2, Benedek Csaba², Fülöp Csongor1', Nagy Örs³, Bățagă Tiberiu1 \\ 1 lst Orthopaedic and Trauma Clinic, Mureș County Emergency Clinical Hospital, Tîrgu Mureș, Romania \\ 2 University of Medicine and Pharmacy of Tîrgu Mureș, Faculty of General Medicine, sixth year medical student, Tîrgu Mureș, Romania \\ 3 |lnd Orthopaedic and Trauma Clinic, Mures County Hospital, Tîrgu Mureș, Romania
}

\begin{abstract}
Arthroplasty is used when there is irreversible damage to the articular cartilage of the knee. It involves implanting a bicompartimental (femoral and tibial components) or a tricompartimental (femoral, tibial and patellar components) prosthesis. It is a very invasive and costly operation, so our objective was to evaluate the necessity of the patellar component.

Material and methods: During our study we've included 39 patients: in 27 cases we used tricompartimental prosthesis, while the other 12 received only the bicompartimental components. Patients were evaluated preoperatively and postoperatively using the International Knee Documentation Comitee score. We've also compared our results with the results of other published authors.

Results: We've found that there is little to no difference between the two groups regarding mobility and complication, however patients with bicompartimentalarthroplasty complained of less pain.

Conclusion: We've found that bicompartimentalarthroplasty - being a less invasive procedure - is better not only in terms of pain management, but there is also less hemorrhaging, shorter intraoperative time is considered, revision is easier and also has financially advantages, both for the patient and for the medical facility.
\end{abstract}

Keywords: knee, arthroplasty, prosthesis, patellar resurfacing

Received: 16 March 2015 / Accepted: 18 July 2015

\section{Introduction}

Knee replacement surgery, knowm also as knee arthroplasty, represents a surgical procedure dedicated to replacement of the knee joint weight-bearing cartilage surfaces with metallic implants. The procedure is usually performed having as indication the relieve of pain and disability and also to allow a continued motion of the knee. The replacement can be partial or total and the most common indications are represented by osteoarthritis, rheumatoid arthritis or traumatic injury.

It is a very invasive procedure that involves numerous risks: deep vein thrombosis, periprosthetic fractures, loss of motion, instability and/or infection.Itis also a very costly procedure - an average tricompartimentalimplant cost per case ranges from $\$ 1.700$ to $\$ 12.000$ [1].

Because of the aforementioned considerations, the aim of this study was to compare the outcome of total knee replacement with patellar resurfacing with those withoutpatellar resurfacing and to compare our results with the results of other authors.

\section{Material and Methods}

A total of thirty nine patients were included in the present study based on age and the severity of osteoarthritis. The sex ratio was 1.8 , while the mean age was 67.3 years. Twenty eight of these patients presented primary osteoarthritis of the knee, while the rest - eleven - presented sec-

* Correspondence to: Árpád Sólyom

E-mail: solyomarpad@yahoo.com ondary osteoarthritis as a result of previous trauma or deformity. Six percent of patients underwent previous open meniscus repair surgeries in their youth; thirty one percent underwent arthroscopy with an average of 3.2 years prior to knee replacement surgery, while thirty one patients had hyaluronic acid joint injections, average 5 years before. All patients suffered from Albach type III and IV osteoarthritis of the knee.

The patients were divided in two groups: twenty seven underwent total knee replacement surgery using tricompartimental prostheses (i.e. femoral, tibial and patellar components) while twelve of them received bicompartimental prostheses (i.e. femoral and tibial components). Prior and after surgery, patients were asked to describe their level of pain using a visual analog scale (VAS); they were also examined using the International Knee Documentation Committee score (IKDC).

The authors have also reviewed a number of articles that focus on the matter of patellar resurfacing vs. patellar conservation. The findings of these authors where compared with the result found during the present study.

\section{Results}

Prior to surgery, the VAS results showed an average of 8 points, meaning the patients suffered from significant knee pain, while the IKDC score in both groups showed values between 41-53 points.

Postoperatively, however, we see a considerable improvement in the patient's scores (Table I, Table II). 
Table I. Postoperative IKDC scores of patients with patellar resurfacing

\begin{tabular}{lcccc}
\hline 3 days & 1 month & 3 months & 6 months & 12 months \\
\hline $39-50$ & $62-69$ & $64-72$ & $68-75$ & $74-91$ \\
\hline
\end{tabular}

Table II. Postoperative IKDC scores of patients without patellar resurfacing

\begin{tabular}{lcccc}
\hline 3 days & 1 month & 3 months & 6 months & 12 months \\
\hline $35-47$ & $61-72$ & $64-70$ & $65-74$ & $84-93$ \\
\hline
\end{tabular}

Postoperatively, there were no early complications, however, in case of the tricompartimentalgroup, two patients had undergone patellar revision surgery after one and a half years, because of anterior compression syndrome.

We've compared our results with similar results of other authors (Table III).

\section{Discussion}

Early knee arthroplastie, being associated frequently with failure to acknowledge the patelo-femoral joint, are frequently accompanied with severe pain at the level of ante- rior knee. However, patellar resurfacing procedures led to a significantly increased patient satisfaction but the scientific community has divergent opinion on this subject (Table IV).

In order to identify those patients with a higher potential to present an improvement in clinical outcomes following this procedure, the concept of selective resurfacing has been introduced and tested. This attempt is also necessary in order to avoid potential complications associated with unnecessary resurfacing [25-32]. The authors who support this procedure consider many patient- and prostheses-related factors as certain prerequisites in favor of the intervention. Among the factors mentioned in the literature as having a favorable effect on patella retention, the age of patients below 65 years, the absence of anterior knee pain or crystalline disease, a relatively well preserved retro-patellar cartilage, anatomical integrity and normal patellar mechanics have been suggested

In the case of patients suffering from different inflammatory arthropathies, Sledge and Ewald suggested that non-resurfacing of the patella in rheumatoid arthritis, for

Table III. Compilation of the results of published authors

\begin{tabular}{|c|c|c|}
\hline Author & Aim of study & Results \\
\hline Tanzer et al. [2] & $\begin{array}{l}\text { effect of femoral component design on the } \\
\text { contact and tracking properties of the unre- } \\
\text { surfaced patella in total knee arthroplasty; }\end{array}$ & $\begin{array}{l}\text { significant changes in patelo-femoral contact areas, pressures and tracking at higher } \\
\text { flexion angles when the native patella was articulated with the femoral component; } \\
\text { surface geometries of posterior stabilized femoral components appear incompatible } \\
\text { with the native patella, as the apex of the retro-patellar ridge impinges on the pros- } \\
\text { thetic intercondylar notch at angles beyond 900; }\end{array}$ \\
\hline Takahasiet al. [3] & $\begin{array}{l}\text { effect of patellar morphology and implant } \\
\text { design on patelo-femoral contact stress } \\
\text { in total knee arthroplasty without patellar } \\
\text { resurfacing; }\end{array}$ & $\begin{array}{l}\text { post-operative osteosclerosis was observed with decreasing patellar facet angle in } \\
\text { case of Genesis II and NexGen implants; } \\
\text { patients treated with Genesis II had significantly more advanced osteosclerosis than } \\
\text { those treated with other implants; } \\
\text { patellar morphology and femoral component geometry influence patelo-femoral con- } \\
\text { tact stress in total knee arthroplasty without patellar resurfacing; }\end{array}$ \\
\hline Munoz-Mahamud et al. [4] & $\begin{array}{l}\text { prospective review of patients who, between } \\
2004 \text { and } 2007 \text {, underwent secondary patel- } \\
\text { lar resurfacing because of anterior knee pain } \\
\text { after a primary total knee arthroplasty; } \\
\text { evaluate the clinical outcomes obtained with } \\
\text { the SPR and compare them with radiological } \\
\text { findings; }\end{array}$ & $\begin{array}{l}63 \% \text { of patients reported improvement after SPR, while patelo-femoral scores (KSS } \\
\text { and WOMAC) showed a statistically significant improvement following the procedure; } \\
\text { no significant changes after SPR in the Insall-Salvati ratio, lateral patellar displace- } \\
\text { ment or tilt; } \\
\text { postoperative complications were patellar component loosening and acute post- } \\
\text { infection; }\end{array}$ \\
\hline Müller et al. [6] & $\begin{array}{l}\text { operating } 436 \text { knees using the LCS meniscal } \\
\text { bearing total knee arthroplasty; }\end{array}$ & $\begin{array}{l}\text { New Jersey Score increased constantly over the 5-year follow-up from } 83 \text { after } 2 \\
\text { years to } 90 \text { after } 5 \text { years; } \\
\text { there is no deterioration which can be attributed to a deterioration in patellar behavior; } \\
\text { nonresurfacing of the patella is a possible solution if the following criteria are met: } \\
\text { kinematics of the arthroplasty allows physiological rotation; } \\
\text { anatomically built prosthesis; } \\
\text { correct alignment; } \\
\text { anatomy of the decelerator/extensor mechanism is respected by the approach; } \\
\text { good ligamentous stability; }\end{array}$ \\
\hline
\end{tabular}

TableIV. Pros and cons of patellar resurfacing

\begin{tabular}{|c|c|}
\hline Arguments in favor of patellar resurfacing [7-12] & Arguments opposing patellar resurfacing [13-24] \\
\hline $\begin{array}{l}\text { reduced pain at the level of anterior knee in the postoperative period; } \\
\text { no need for secondary resurfacing; } \\
\text { higher patient satisfaction; } \\
\text { superior overall function; } \\
\text { low complication rate; } \\
\text { less expensive procedure and not time-consuming when performed during } \\
\text { standard knee arthroplasty; } \\
\text { prolonged exposure to high compressive forces can cause cartilage } \\
\text { erosion, as a result of the unphysiological contact between cartilage and } \\
\text { metal }\end{array}$ & $\begin{array}{l}\text { no evidence exists of patellae affected by metal-cartilage contact become symp- } \\
\text { tomatic; } \\
\text { the proportion of revisions attributable to the resurfaced patella decreased from } \\
\text { almost } 50 \% \text { in the } 1980 \text { s to approx } 12 \% \text { nowadays; } \\
\text { decreased rates of patelo-femoral complications }(4-5 \%) \\
\text { similar clinical results in patients with and without resurfacing } \\
\text { superior conservation of patellar bone; } \\
\text { reduced the risk of patellar osteonecrosis; } \\
\text { physiological patelo-femoral kinematics; } \\
\text { ability to withstand high patelo-femoral forces in active patients without any concern } \\
\text { of prosthetic wear or failure; } \\
\text { lower intra- and post-operative complications (they are more frequently associated } \\
\text { with patellar resurfacing) }\end{array}$ \\
\hline
\end{tabular}


instance, may favor recurrent inflammation resulting from the continued release of sequestered antigen from the retained cartilage [33].

In case the patella remains un-resurfaced, the proper selection of prosthetic design, using a patella-friendly femoral component has proven to be extremely important [3440]. The supporters of the non-resurfacing strategy prefer to attempt to provide a a better accommodation with the native patella femoral components, using an anatomically shaped trochlear configuration. In case of bicompartmental knee arthroplasty, the patella left non-resurfaced is exposed to the metallic surface of the femoral component, process that leads in time to the so-called "bedding in" in order to adapt to the geometry of the opposing surface. The complex process named "stress contouring" represents a type of biological remodeling, gradually adapting different components between them in order to ensure a superior functionality, such as the retro-patellar surface, the subchondral bone plate and the trochlea shape [41]. Keblish and Greenwald noticed that patella exposure to a constant radius of curvature in conditions of uniform femoral geometry is associated with a minimal remodeling, while exposure of patella to a non-anatomical design is associated with an excessive remodelling process [42].

\section{Conclusion}

The results of this present study correspond with the results of other internationally acclaimed authors, as we see a general improvement postoperatively. There are always some discrepancies, which are mostly due to subtle individual differences of patients.

All in all, the authors have concluded that knee replacement surgery without patellar resurfacing is a much more advantageous technique in terms of fewer complications (ex. anterior compression syndrome, patella wear and fracture, knee pain, harder revision) and shorter operating time (general operating time in case of knee replacement with patellar resurfacing is one hour and twenty three minutes, while in case of operations without patellar resurfacing, it is shortened to one hour and fourteen minutes).

\section{References}

1. Robinson JC1, Pozen A, Tseng S, et al. Variability in costs associated with total hip and knee replacement implants. J Bone Joint Surg Am. 2012;94:1693-1698.

2. Tanzer M, McLean CA, Laxer E, et al. Effect of femoral component designs on the contact and tracking characteristics of the unresurfaced patella in total knee arthroplasty. Canadian J Surg. 2001;44:127-133.

3. Takahashi A, Sano H, Ohnuma M, et al. Patellar morphology and femoral component geometry influence patellofemoral contact stress in total knee arthroplasty without patellar resurfacing, Knee SurgSports TraumatolArthrosc. 2012;20:1787-1795.

4. Muñoz-Mahamud E, Popescu D, Nuñez E, et al. Secondary patellar resurfacing in the treatment of patellofemoral pain after total knee arthroplasty. Knee Surg Sports Traumatol Arthrosc. 2011;19:1467-1472.

5. Oztuna V, Karatosun V, Unver B, et al. An alternative patellar resurfacing technique in knee replacement: patellofemoralfascial interposition arthroplasty. Knee Surg Sports Traumatol Arthrosc. 2007; 15:1210-1214.

6. Müller W, Wirz D. The patella in total knee replacement: does it matter? 750 LCS total knee replacements without resurfacing of the patella. Knee Surg, Sports Traumatol, Arthrosc. 2001;9 [Suppl1]:S24-S26.
7. Brander VA, Stulberg SD, Adams AD, et al, Predicting total knee replacement pain. A prospective, observational study. Clin Orthop Relat Res. 2003;416:27-36.

8. Levani JP, McLeod HC, Freeman MAR. Why not resurface the patella? J Bone Jt Surg. 1983,65-B:448-451.

9. Ranawat CS. The patellofemoral joint in total condylar knee arthroplasty. Clin Orthop Relat Res. 1986,205:93-99.

10. Scott WN, Kim H. Resurfacing the patella offers lower complication and revision rates. Orthopedics. 2000;24:24.

11. Waters TS, Bentley G. Patellar resurfacing in total knee arthroplasty. J Bone Jt Surg. 2003;85-A:212-217.

12. Forster $\mathrm{H}$, Fisher J, The influence of continuous sliding and subsequent surface wear on the friction of articular cartilage. Proc Inst Mech Eng. 1999;213:329-345.

13. Soudry M, Mestriner LA, Binazzi R, et al. Total knee arthroplasty without patellar resurfacing. Clin Orthop Relat Res. 1986;205:166-170.

14. Brick GW, Scott RD, The patellofemoral component of total knee arthroplasty. Clin Orthop Relat Res. 1988;231:163-178.

15. Sharkey PF, Hozack WJ, Rothman $\mathrm{RH}$, et al. Why are total knee arthroplasties failing today? Clin Orthop Relat Res. 2002;404:7-13.

16. Barrack RL, Bertot AJ, Wolfe MW, et al. Patellar resurfacing in total knee arthroplasty: A prospective randomised double blinded study with five to seven years of follow-up. J Bone Jt Surg. 2001;83-A:1376-1381.

17. Boyd AD, Ewald FC, Thomas WH, et al. Long-term complications after total knee arthroplasty with or without resurfacing of the patella. J Bone Jt Surg. 1993;75-A:674-681.

18. Larson CM, Lachiewicz PF. Patellofemoral complications with the InsallBurstein II posterior stabilised total knee arthroplasty. J Arthroplasty. 1999;14:288-292.

19. Meneghini RM. Should the patella be resurfaced in primary total knee arthroplasty? An evidence-based analysis. J Arthroplasty. 2008;23(Suppl 1):11-14.

20. Wood DJ, Smith AJ, Collopy D, et al. Patellar resurfacing in total knee arthroplasty: a prospective randomised trial. J Bone Jt Surg. 2002;84A:187-193.

21. Abraham W, Buchanan JR, Daubert H, et al. Should the patella be resurfaced in total knee arthroplasty? Efficacy of patellar resurfacing. Clin Orthop Relat Res. 1988;236:128-134.

22. Cameron H.U., Fedorkow D.M., The patella in total knee arthroplasty. Clin Orthop Relat Res. 1982;165:197-199.

23. Feller JA, Bartlett RJ, Lang DM, Patellar resurfacing versus retention in total knee arthroplasty. J Bone JtSurg1996, 78:226-228.

24. Keblish PA, Varma AK, Greenwald SA. Patellar resurfacing or retention in total knee arthroplasty: a prospective study of patients with bilateral replacement. J Bone Jt Surg. 1994, 76:930-937.

25. Abraham W, Buchanan JR, Daubert $H$, et al. Should the patella be resurfaced in total knee arthroplasty? Efficacy of patellar resurfacing. Clin Orthop Relat Res. 1988;236:128-134.

26. Brick GW, Scott RD. The patellofemoral component of total knee arthroplasty. Clin Orthop Relat Res. 1988;231:163-178.

27. Hasegawa M, Ohashi T. Long-term clinical results and radiographic changes in the nonresurfaced patella after total knee arthroplasty: 78 knees followed for mean 12 years. Acta Orthop Scand. 2002;73:539 545.

28. Kim BS, Reitman RD, Schai PA, et al. Selective patellar non-resurfacing in total knee arthroplasty. 10 year results. Clin Orthop Relat Res. 1999;367:81-88.

29. Levitsky KA, Harris WJ, McManus J, et al. Total knee arthroplasty without patellar resurfacing. Clin Orthop Relat Res. 1993;286:116-121.

30. Picetti GD, McGann WA, Welch RB. The patellofemoral joint after total knee arthroplasty without patellar resurfacing. J Bone Jt Surg. 1990;72A:1379-1382.

31. Scott RD, Reilly DT. Pros and cons of patellar resurfacing in total knee replacement. Orthop Trans. 1980;4:328-329.

32. Shoji H, Yoshino S, Kajino A, Patellar replacement in bilateral total knee arthroplasty. J Bone Jt Surg. 1989;71-A:853-856.

33. Sledge CB, Ewald FC. Total knee arthroplasty experience at the Robert Breck Brigham Hospital. Clin Orthop Relat Res. 1979;145:78-84.

34. Bourne R.B., Burnett R.S.J., The consequences of not resurfacing the patella. Clin Orthop Relat Res. 2004;428:166-169.

35. Hwang $\mathrm{BH}$, Yang $\mathrm{IH}$, Han $\mathrm{CD}$, Comparison of patellar retention versus resurfacing in LCS mobile-bearing total knee arthroplasty. Knee Surg Sports Traumatol Arthrosc. 2012;20:524-531.

36. Ma HM, Lu YC, Kwok TG, et al. The effect of the design of the femoral component on the conformity of the patellofemoral joint in total knee replacement. J Bone Jt Surg. 2007;89:408-412. 
37. Matsuda S, Ishinishi T, White SE, et al. Patellofemoral joint after total knee arthroplasty: effect on contact area and contact stress. J Arthroplasty. 1997;12:792-796.

38. Matsuda S, Ishinishi T, Whiteside LA. Contact stresses with an unresurfaced patella in total knee arthroplasty: the effect of femoral component design. Orthopedics. 2000;23:213-218.

39. O'Brien S, Spence DJ, Ogonda LO, et al. LCS mobile bearing total knee arthroplasty without patellar resurfacing. Does the unresurfacedpatella affect outcome? Survivorship at a minimum 10-year follow-up.Knee. doi:10.1016/j.knee. 2012;2011.07.002.

40. Theiss SM, Kitziger KJ, Lotke PS, et al. Component design affecting patellofemoral complications after total knee replacement. Clin Orthop Relat Res. 1996;326:183-187.

41. Smith SR, Stuart P, Pinder IM. Non-resurfaced patella in total knee arthroplasty. J Arthroplasty. 1989;4 (Suppl):81-86.

42. Keblish PA, Varma AK, Greenwald SA. Patellar resurfacing or retention in total knee arthroplasty: a prospective study of patients with bilateral replacement. J Bone Jt Surg. 1994;76:930-937. 